\title{
Commentary
}

\section{COVID-19, Medicine, and Sports}

\author{
Ron Gilat, M.D., and Brian J. Cole, M.D.
}

\begin{abstract}
The COVID-19 outbreak has brought our lives to a sudden and complete lockdown. While the numbers of confirmed cases and deaths continue to rise, people around the world are taking brave actions to mitigate transmission and save lives. The role that sports play in this pandemic is unprecedented, fascinating, and reveals the immense impact sports has on every aspect of our lives. We must all do our part to keep each other safe until this outbreak subsides and sports and humanity are back to being greater than ever. Level of Evidence: Level V.
\end{abstract}

C oronavirus disease 2019 (COVID-19) has swiftly changed humanity as we know it. The ramifications of COVID-19 on our global civilization have just begun to unfold and will most probably continue to do so for the next several decades. It is probably more than we can comprehend or imagine at this time. Looking around corners has become particularly challenging, and assumptions about the future change on a daily if not hourly basis.

With our world coming to a complete stop in a sudden and unprecedented way, most organized sports activities have all but vanished. We understand now more than ever the leadership role sports plays in our society. Big sports events that resumed during the midst of the COVID-19 outbreak are now being referred to as huge "biological bombs" due to spreading of the virus during these events. One example is the soccer game between Atalanta (from Italy) and Valencia (from Spain) that was held in Bergamo, Italy, in February 19 , 2020. Experts assume that the 45,792 fans attending this UEFA Champions League exchanged the virus and

From Midwest Orthopedics at Rush University Medical Center, Chicago, Illinois, U.S.A.

The authors report the following potential conflict of interest or source of funding: B.J.C. reports grants, personal fees, and non-financial support from Arthrex during the conduct of the study; other from Aesculap, other from Athletico, personal fees and other from Elsevier publishing, other from JRF Ortho, other from the National Institutes of Health, personal fees and other from Operative Techniques in Sports Medicine, personal fees from Ossio, personal fees and other from Regentis, and other from Smith $\theta$ Nephew, outside the submitted work. Full ICMJE author disclosure forms are available for this article online, as supplementary material.

(C) 2020 THE AUTHORS. Published by Elsevier Inc. on behalf of the Arthroscopy Association of North America. This is an open access article under the CC BY-NC-ND license (http://creativecommons.org/licenses/by-nc-nd/4.0/).

2666-061X/20509

https://doi.org/10.1016/j.asmr.2020.04.003 contributed to the massive outbreak of the virus in Italy and Spain. Adam Silver, the commissioner of the National Basketball Association, was of the first to respond to the migration of the pandemic in the United States, with his crucial decision to postpone the rest of the National Basketball Association season. His decision might have been the "tipping point," turning the United States from passive to active mode. After that, many more sporting events throughout the world were postponed or cancelled, including the 2020 Tokyo Olympics.

Since then, virtually every organized sport at any level and any age has been cancelled and indefinitely postponed. With the rise in identified cases and death toll, most countries worldwide are increasing their "stay-at-home" restrictions, and many citizens are under mandatory confinement. Consequentially, recreational athletes and "weekend warriors" also have been benched during these turbulent times. Not many possibilities for resuming sports activities are available, given the combination of social distancing with the closure of parks, gyms, and sports venues. Notably, it is difficult to imagine what exactly has to happen to allow athletes to safely engage in physical contact and furthermore, to allow fans to gather in a fashion similar to what we have come to enjoy for thousands of years.

Health care providers specializing in sports medicine who attend to all types of athletes must quickly adapt to this new and hopefully transient situation. First and foremost, practices are now finding the safest way to continue to serve their community to the best of their ability. It starts with keeping up to date with the rapidly changing Centers for Disease Control and Prevention instructions and implementing these to keep staff and patients safe. Efforts should be made to maximize the use of "telemedicine" to continue providing care to patients and to identify essential 
problems that require being seen in clinic, a physical examination, imaging for definitive assessment, emergency department triage, and defining and treating conditions that require urgent and timesensitive surgical care. Staff should be stringent with their own protection at all times, as they can easily become "super-spreaders," infecting whole communities (including their coworkers and families). As of today, most protocols include strategies that mirror universal precautions, including wearing of a surgical mask by all in the health care setting.

The financial crisis had already and will continue to take its toll for the foreseeable future. There is no business model for a company losing (close to all) income immediately, while the world is financially shut down for an unknown period of time. Millions have or will lose their jobs, be laid off, or furloughed with the prospects of returning to work at the proper time. That is also true for sports medicine health care providers and related businesses. The restriction on participation in all team sports and many other individual sports, together with restrictions on elective surgery and other revenue-producing services, has left many institutions on the verge of financial bankruptcy. We must stay positive and (virtually) together during these times and believe that this is only temporary, and we will prevail. Many institutions are attempting to downsize to a versatile "skeleton" that can continue to provide highend medical services at minimum expenses with the ability to remain nimble and flex upwards to incorporate back all former services and human resources as this outbreak subsides.

There are many unanswered questions and many more will arise as we better understand our circumstances. For example, whether players affected by COVID-19 will endure any long-term effects on their health or game performance is unknown. Are we prepared to treat the many new patients with injuries due to unconditioned musculature? How should we brace for the next winter or the one after that? Will "telemedicine" affect the role of the hands-on physical examination? How do we weigh risk-vs-benefit in the care of essential or urgent musculoskeletal cases during this outbreak? Tests regulations? Vaccines? And so many more.

We understand now more than ever that sports keep our body and mind healthy and bring us together. We are confident we and our patients will return to play sports, there will be injuries and persistent need for our services, and we will do what we love to do: to get them back to doing what they love to do. 